\title{
Retinoic acid induces alveolar regeneration in the adult mouse lung
}

\author{
M. Hind, M. Maden
}

Retinoic acid induces alveolar regeneration in the adult mouse lung. M. Hind, M. Maden. (C) ERS Journals Ltd 2004.

ABSTRACT: Recent data suggests that exogenous retinoic acid (RA) can induce alveolar regeneration in a mouse and a rat model of experimental emphysema and disrupted alveolar development. This may be because RA is required during normal alveolar development and the subsequent provision of RA reawakens the gene cascades used during development.

Here, additional evidence that $\mathrm{RA}$ is required during alveologenesis in the mouse is provided by showing that disulphiram disrupts this process. A further model of disrupted alveolar development using dexamethasone administered postnatally is then described, and it is further shown that RA administered to these adult mice restores the lung architecture to normal.

Alveolar regeneration with retinoic acid may therefore be an important novel therapeutic approach to the treatment of respiratory diseases characterised by a reduced gas-exchanging surface area, such as bronchopulmonary dysplasia and emphysema.

Eur Respir J 2004; 23: 20-27.
Medical Research Council Centre for Developmental Neurobiology, King's College London, London, UK

Correspondence: M. Maden, MRC Centre for Developmental Neurobiology, 4th floor New Hunt's House, King's College London, Guy's Campus, London Bridge, London SE1 1UL UK.

Fax: 442078486798

E-mail: malcolm.maden@kcl.ac.uk

Keywords: Alveolar regeneration, dexamethasone, lung, mouse, regeneration, retinoic acid

Received: December 192002

Accepted after revision: August 142003

This work was funded by The Wellcome Trust via a Wellcome Trust Research Training Fellowship to M. Hind.
The ability of adult mammals to regenerate organs seems to be limited to only one, the liver, apart from the unique phenomenon of antler regeneration in deer. This is in striking contrast to the remarkable abilities of the Urodele amphibians where limbs, tails, jaws, spinal cords, forebrain, lens, retina and gills can all regenerate [1]. However, on a tissue rather than a whole organ level mammals can, of course, continually replace their epidermis, gut endoderm and blood cells. With the discovery of neural stem cells [2], neurones may also be included in this regenerative tissue category.

Perhaps, therefore, there may be a greater regenerative ability present in mammals than has hitherto been realised. An excellent example of this is the adult mammalian lung. It was recently discovered that retinoic acid (RA) can induce the regeneration of lung alveoli in the experimentally damaged adult rat lung [3]. The experimental damage induced was the instillation of elastase into the trachea, which destroys the alveoli, resulting in a vastly reduced gas-exchanging surface area (SA) and this was developed as a model for the human disease of emphysema. This effect of RA was also seen in the tight-skin mutant mouse, which has a genetic failure of alveolar development, and in postnatal rats treated with dexamethasone (Dex) [3].

It would have a dramatic impact on human health if RA induced alveolar regeneration in human diseased lungs that have decreased gas-exchanging SA, such as those displaying emphysema. Emphysema and chronic bronchitis together comprise the clinical syndrome of chronic obstructive pulmonary disease (COPD) that is predicted to become the third commonest cause of death worldwide by 2020 [4]. Currently, there are no effective treatments for COPD save supplemental oxygen and

For editorial comments see page 3. lung transplantation, and the outlook for affected patients is bleak [5]. However, subsequent studies on RA-induced alveolar regeneration have not confirmed these striking results. Some have shown only a partial rescue of alveolar SA in elastase-treated rats [6, 7], and others have reported no effect of RA at all $[8,9]$. In the work reported here, a mouse model for regeneration studies using Dex, which inhibits alveologenesis, administered during the period of alveologenesis is described. Subsequent RA treatment of these mice, when adults, rescues the deleterious effects of Dex and induces histological regeneration of the lung structure, thus confirming the data of MASSARO and MASSARO [3].

It is interesting to consider why RA may have such an effect on an adult tissue, since it is primarily known for its important role as a signalling molecule in several developing systems [10-12]. This concept implies that RA should be crucially involved in alveologenesis in the first place and indeed, this seems to be the case. Retinoids are readily detectable by highperformance liquid chromatography (HPLC) in the postnatal lung [13-15], the RA-synthesising enzymes, receptors and cytoplasmic-binding proteins are present [14, 16-18], and mice made mutant for the retinoic acid receptor $\gamma$ gene fail to form alveoli correctly [19]. In the work described here, studies on the role of RA during mouse alveologenesis are continued by showing that disulphiram, a compound that inhibits RA synthesis, inhibits alveologenesis.

\section{Materials and methods}

\section{Animals}

All experiments were conducted in accordance with local ethics committee guidelines. The mice used were of the outbred 
TO strain obtained from Harlan (Southampton, UK). Both males and females were used, but they were analysed separately in case any differences could be detected in the results. Postnatal day (P)0 was defined as the day of birth, thus a P2 pup was aged $48 \mathrm{~h}$.

\section{Dosing}

Disulphiram (Sigma, Poole, UK) was dissolved in dimethylsulphoxide (DMSO; Sigma) and peanut oil (vehicle) at a concentration of $2.5 \mathrm{mg} \cdot \mathrm{kg}^{-1}$ and given as an intraperitoneal injection of $10 \mu \mathrm{L}$ daily for 10 days from P2-14 with a 2-day break on P8 and P9. Controls received the vehicle only. Disulphiram and control animals were killed at P23. Dex (Sigma) was dissolved in phosphate-buffered saline (PBS) and given as a $10-\mu \mathrm{L}$ subcutaneous injection at three different doses to three groups of animals. The doses were $0.05,0.2$ and $0.4 \mathrm{mg} \cdot \mathrm{kg}^{-1}$ and they were administered for 10 days from P2-14 with a 2-day break on P8 and P9. Controls received only PBS injections. Animals were killed at two time points, P30 and P90. All-trans-RA (Sigma) was dissolved in DMSO and peanut oil (Sigma) at a dose of $2 \mathrm{mg} \cdot \mathrm{kg}^{-1}$ and was administered as a $50-\mu \mathrm{L}$ intraperitoneal injection for a period of 10 days from P42-54 with a 2-day break on P48 and P49. Controls received DMSO/peanut oil only. Controls and RA-treated animals were killed at P90.

\section{Histology}

In all cases the lungs were carefully removed from the thorax and intubated with a 22-gauge cannula. The lungs were inflated to a standard pressure of $20 \mathrm{cmH}_{2} \mathrm{O}$ with $4 \%$ paraformaldehyde, after which the trachea was ligated and the tissues placed in $4 \%$ paraformaldehyde for $48 \mathrm{~h}$. The tissues were briefly placed in $30 \%$ alcohol and lung volumes calculated by fluid displacement. The lungs were then processed, embedded in paraffin wax, and 5- $\mu \mathrm{m}$ sections were stained with haematoxylin and eosin and examined by light microscopy.

\section{Morphometry}

Sections were analysed on a light microscope linked to a digital imaging system. Images were acquired at $10 \times$ objective and processed using ImageProPlus analysis software (DataCell Ltd, Finchampstead, UK). Large nonalveolar structures (e.g. blood vessels) were removed from the image and the mean chord length $(\mathrm{Lm})$ calculated. Each section produced at least five nonoverlapping fields and at least 10 sections were analysed for each animal resulting in at least 50 nonoverlapping fields. This produced a $95 \%$ confidence interval of $\pm 5 \%$ of the mean. Following WEIBEL [20], knowledge of the Lm and lung volume allows gas-exchanging SA to be calculated. All data are expressed as mean \pm SEM.

\section{High-performance liquid chromatography analysis}

Retinoids were extracted from $200-500 \mathrm{mg}$ of lung tissue according to the method of THALLER and EICHELE [21] by homogenising the tissue in $1 \mathrm{~mL}$ of stabilising solution $\left(5 \mathrm{mg} \cdot \mathrm{mL}^{-1}\right.$ ascorbic acid, sodium ethylenediamine tetraacetic acid in PBS, pH 7.3). The homogenate was extracted twice with two volumes of 1:8 methyl acetate/ethyl acetate, with butylated hydroxytoluene as an antioxidant, and then dried down over nitrogen. The extract was resuspended in $100 \mu \mathrm{L}$ methanol, centrifuged at high speed to remove any particulate matter and placed into an autosampler vial for analysis.

Reverse-phase HPLC was performed using a Beckman System Gold Hardware (Beckman, High Wycombe, UK) with a photodiode array detector and a $5 \mu \mathrm{m} \mathrm{C}_{18}$ LiChrocart column (Merck) with an equivalent precolumn. The mobile phases used were those of ACHKAR et al. [22], which allows a good separation of the RAs and retinols. The flow rate was $1.5 \mathrm{~mL} \cdot \mathrm{min}^{-1}$ using a gradient of acetonitrile/ammonium acetate (15 mM, pH 6.5) from 40-67\% acetonitrile in 35 min followed by $100 \%$ acetonitrile for an additional $25 \mathrm{~min}$. Individual retinoids could be identified according to their ultraviolet absorption spectra.

\section{Results}

Disruption of endogenous retinoic acid synthesis results in disruption of normal alveologenesis

There are two retinaldehyde dehydrogenase enzymes, RALDH1 and RALDH2, which have been shown to be present in the postnatal mouse lung in specific temporal and spatial patterns that are associated with different patterns of alveolar cell proliferation [14]. To assess the role of RA synthesis during normal alveologenesis, the aldheyde dehydrogenase inhibitor disulphiram was used. Although disulphiram is not a specific inhibitor of the RALDHs, it has been previously shown to block RA synthesis in the chick limb bud, and that RA application rescues limb bud outgrowth [23].

A group of six mice pups was treated with disulphiram during the period of maximum alveolar proliferation, from P2-14. A group of seven pups was treated with PBS only (controls). Disulphiram treatment resulted in the disruption of normal alveolar formation. At P23, the disulphiramtreated animals had fewer, larger alveoli and there was no evidence of secondary septae formation (fig. 1). It was also noticeable that the alveolar walls were thicker than normal which, together with the lack of secondary septae are features of an architecturally immature lung (fig. 1). When this effect was quantified using morphometry (fig. 1c), it was clear that disulphiram treatment during alveolar formation resulted in a significant increase in $\mathrm{Lm}(\mathrm{p}<0.01)$ at $\mathrm{P} 23$, suggesting $\mathrm{RA}$ is required for normal alveologenesis. These results support earlier studies that demonstrated that disruption of RA signalling by mutating the RA receptor $\gamma$ [19] is associated with abnormal alveolar formation.

\section{Postnatal dexamethasone disrupts alveologenesis in the mouse}

Firstly, to determine an effective dose of Dex, groups of mice $(\mathrm{n}=6-10)$ were treated with $0.05,0.2$ or $0.4 \mathrm{mg} \cdot \mathrm{kg}^{-1}$ Dex dissolved in PBS or PBS alone (controls) daily for 10 days throughout the period of alveolar formation (P2-14). The animals were killed at P30, the lungs removed and fixed to a standard pressure and sections taken for morphometric analysis. Figure 2 shows the increasingly enlarged airspaces with increasing doses of Dex. Calculations of the Lm demonstrated that there is a dose-dependent increase in Lm at P30 with increasing doses of Dex (fig. 2e). There was no significant difference from control at the lowest dose of Dex, a moderate effect with the intermediate dose and a strong effect at the highest dose.

Secondly, to determine the relationship between length of Dex treatment and Lm, groups of mice $(n=4-6)$ for either 3, 7 or 10 days were treated from P2 with a dose of $0.4 \mathrm{mg} \cdot \mathrm{kg}^{-1}$ (the highest dose). The animals were sacrificed at P30, the 

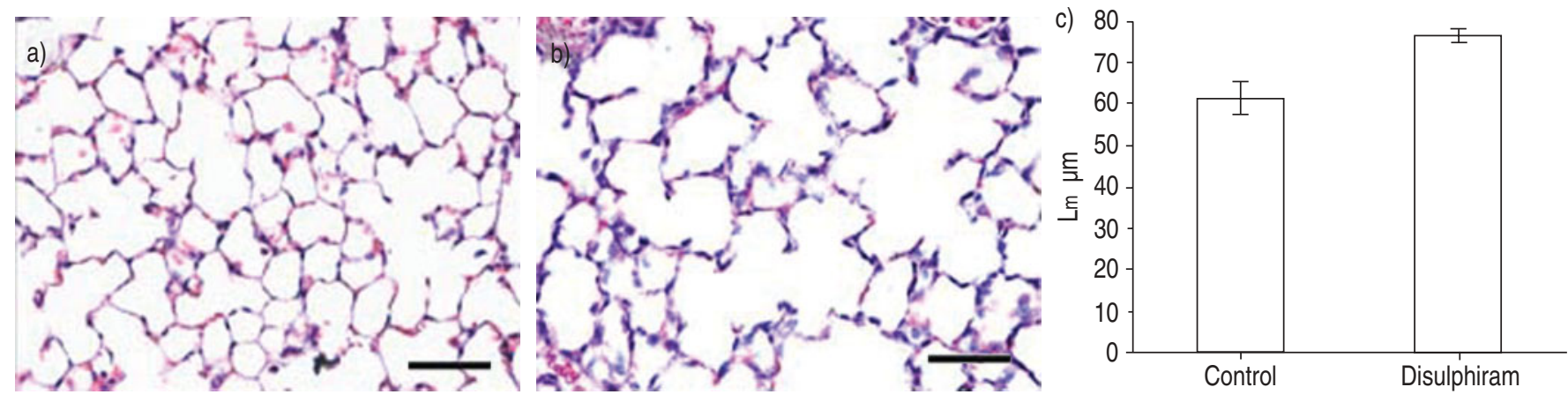

Fig. 1. - Inhibition of endogenous retinoic acid synthesis disrupts normal alveolar formation. a) Representative photomicrograph of a normal P23 mouse lung showing typical alveolar architecture. b) Disulphiram-treated P23 lung at the same magnification as a) showing fewer, larger airspaces with thicker alveolar walls consistent with an immature appearance. Scale bars $=50 \mu \mathrm{m}$. c) Calculation of the average distance between alveolar walls $(\mathrm{Lm})$ demonstrates that disulphiram treatment during alveologenesis $(n=6)$ significantly increased $(\mathrm{p}<0.01) \mathrm{Lm}$ compared with controls $(\mathrm{n}=7)$ at $\mathrm{P} 23$.
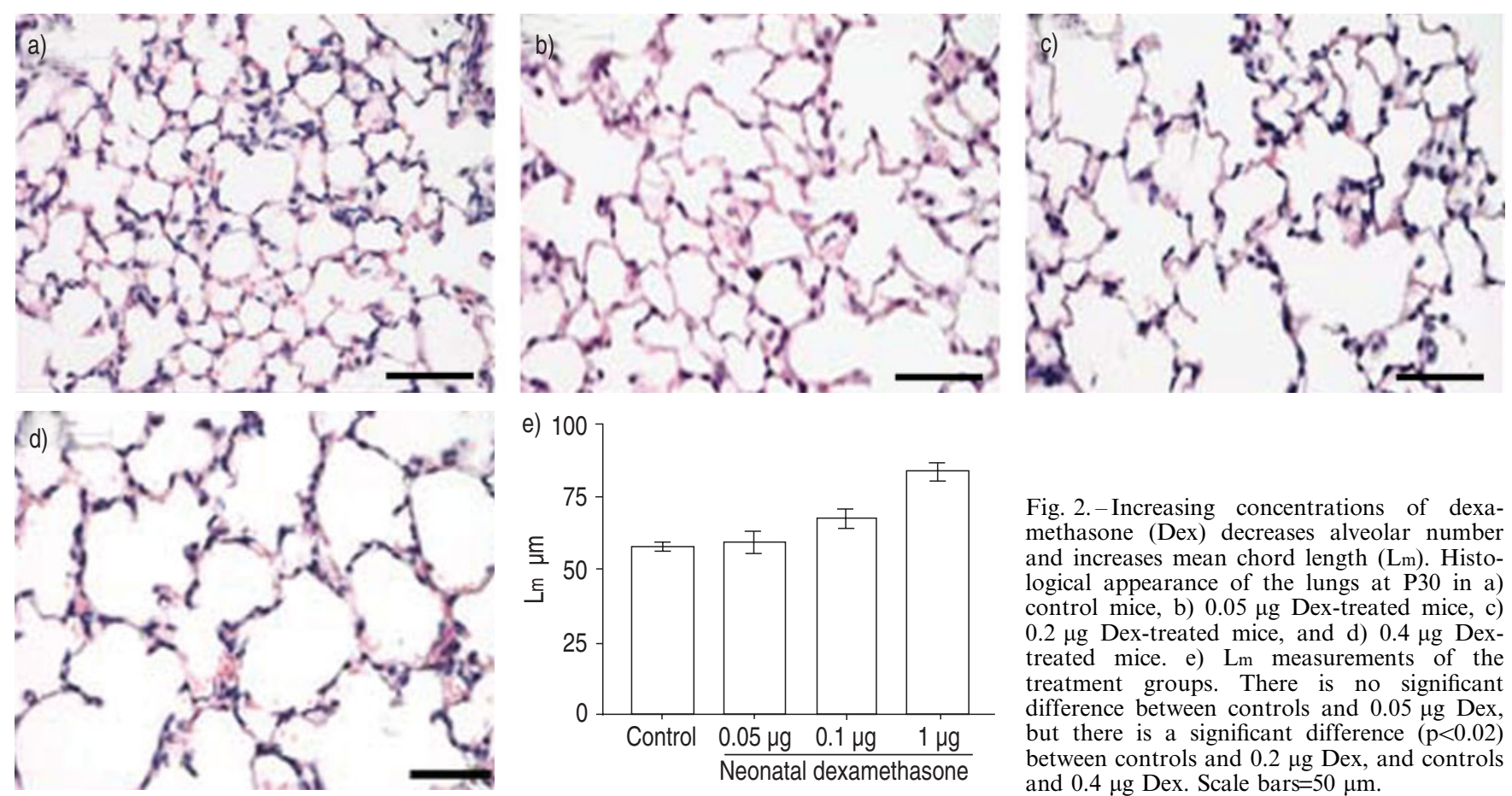

Fig. 2. - Increasing concentrations of dexamethasone (Dex) decreases alveolar number and increases mean chord length (Lm). Histological appearance of the lungs at P30 in a) control mice, b) $0.05 \mu \mathrm{g}$ Dex-treated mice, c) $0.2 \mu \mathrm{g}$ Dex-treated mice, and d) $0.4 \mu \mathrm{g}$ Dextreated mice. e) $\mathrm{Lm}$ measurements of the treatment groups. There is no significant difference between controls and $0.05 \mu \mathrm{g}$ Dex, but there is a significant difference $(\mathrm{p}<0.02)$ between controls and $0.2 \mu \mathrm{g}$ Dex, and controls and $0.4 \mu \mathrm{g}$ Dex. Scale bars $=50 \mu \mathrm{m}$.

lungs removed, perfusion fixed and the Lm calculated. A similar relationship to increasing dose exists. Figure 3 shows the increasingly enlarged airspaces with increasing time of Dex treatment. Figure 3e shows this in terms of $\mathrm{Lm}$ where there is a clear relationship between the length of treatment with Dex and the increase in $\mathrm{Lm}$. There is no significant difference between controls and 3 days of treatment, but between controls and 5 and 10 days treatment the $\mathrm{Lm}$ is significantly increased $(\mathrm{p}<0.001)$.

Using this high dose of Dex for the full treatment time of 10 days results in a significant effect on body size at P15 (fig. 4a). However, when Dex treatment is stopped there is a catch-up period of growth (fig. 4b) such that final body weights vary by $<20 \%$ at P90 (fig. 5e). Lower doses of Dex disrupt alveolar architecture but have no effect on final body weight at P90. Despite the evidence of a catch-up period of somatic growth following the stopping of Dex, it is important to emphasise that the effect on alveolar architecture is long term and probably permanent. There are fewer, large airspaces and a grossly simplified alveolar structure at P90. An example of a control and a Dex-treated animal at P150 demonstrating the longevity of the Dex treatment is shown in figure 4. This is in general agreement with previous studies in the rat [24, 25] confirming the presence of a "critical period" in the postnatal development of alveoli in the mouse.

\section{Does administered retinoic acid get to the lung?}

To determine the pharmacokinetics of intraperitoneal treatment with RA and to ensure that such a dose does indeed reach the lung, retinoids were extracted from the blood and lungs of adult animals at $5 \mathrm{~min}, 15 \mathrm{~min}, 30 \mathrm{~min}, 1 \mathrm{~h}, 2 \mathrm{~h}$, $4 \mathrm{~h}, 12 \mathrm{~h}$ and $18 \mathrm{~h}$ following a single dose of RA $(2.0 \mathrm{mg} \cdot \mathrm{kg}$ body weight ${ }^{-1}$ ). The experiment was performed in duplicate. There is a rapid uptake of RA into both the blood (data not 

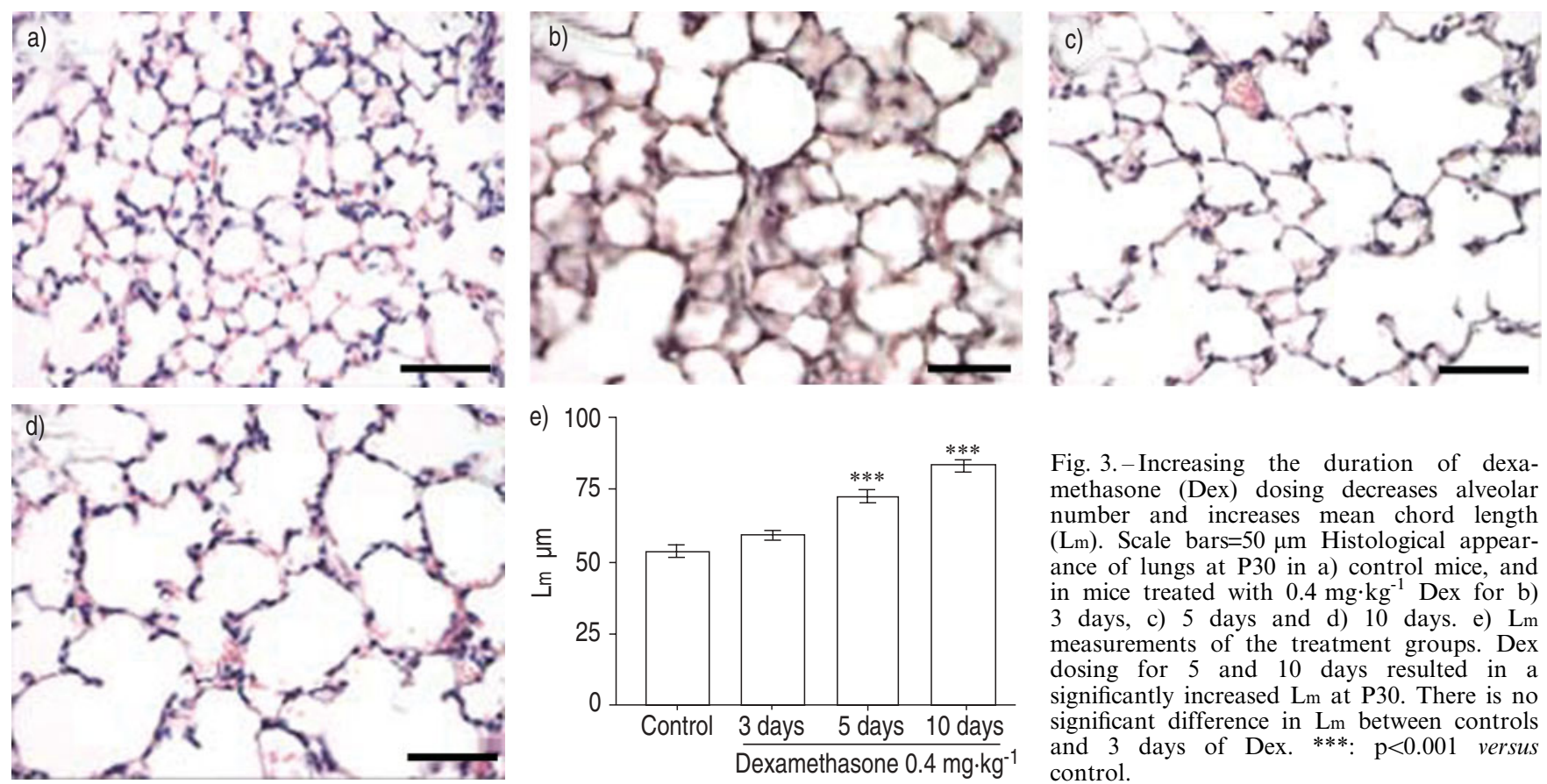

e) 100

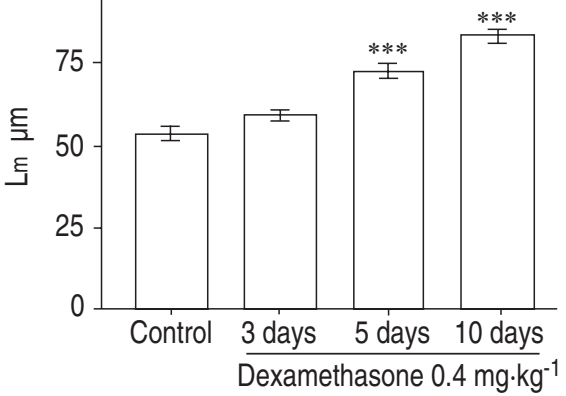

Fig. 3.- Increasing the duration of dexamethasone (Dex) dosing decreases alveolar number and increases mean chord length $(\mathrm{Lm})$. Scale bars $=50 \mu \mathrm{m}$ Histological appearance of lungs at P30 in a) control mice, and in mice treated with $0.4 \mathrm{mg} \cdot \mathrm{kg}^{-1}$ Dex for b) 3 days, c) 5 days and d) 10 days. e) $\mathrm{Lm}$ measurements of the treatment groups. Dex dosing for 5 and 10 days resulted in a significantly increased $\mathrm{Lm}$ at P30. There is no significant difference in $\mathrm{Lm}$ between controls and 3 days of Dex. ***: $\mathrm{p}<0.001$ versus control.
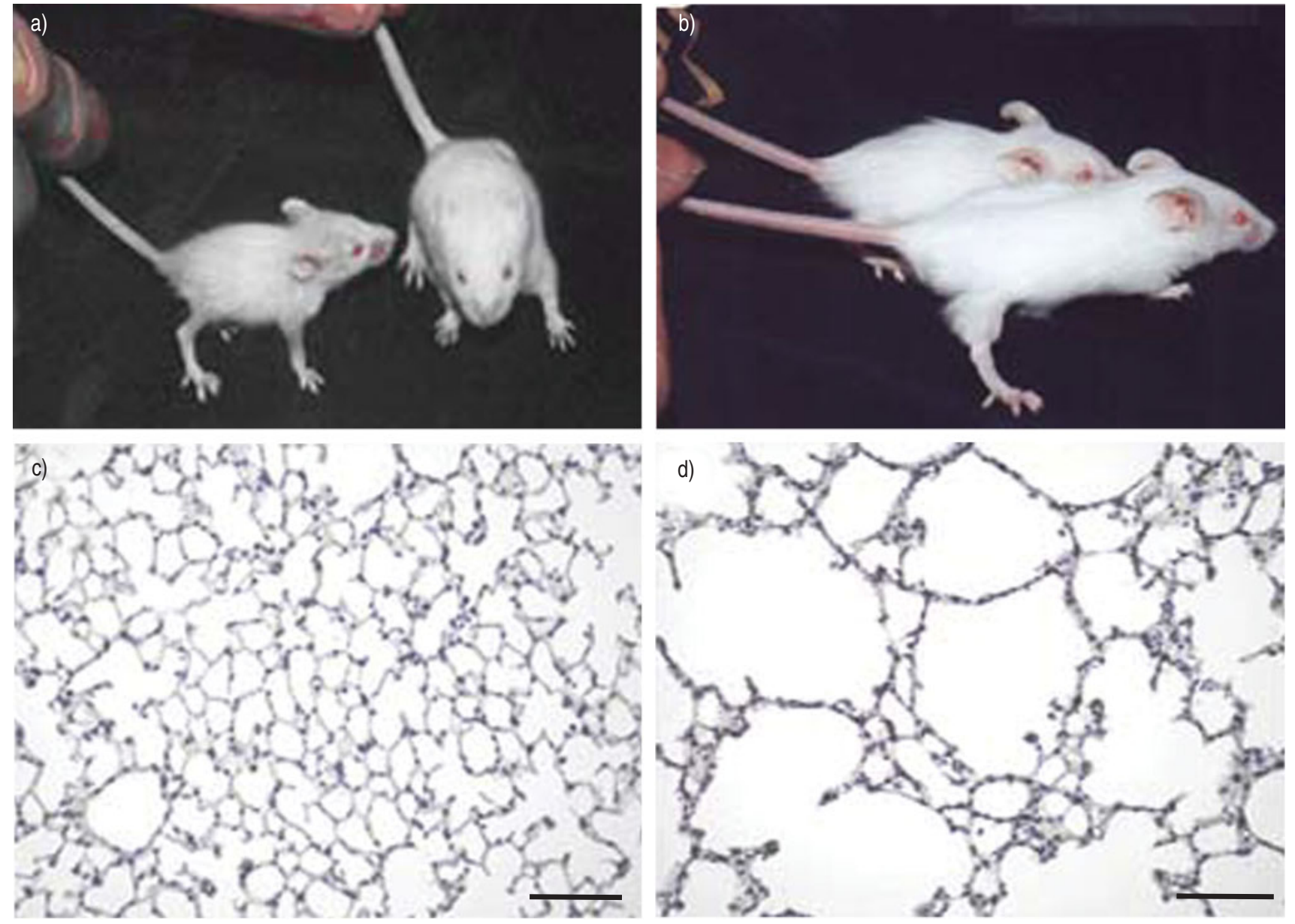

Fig. 4. - Effects of dexamethasone (Dex) on somatic growth and long-term lung structure. a) 10 days of Dex $\left(0.4 \mathrm{mg} \cdot \mathrm{kg}^{-1}\right)$ has an obvious developmental delay in the experimental animal (left) compared with its sibling control (right) at P15. b) By P25 there has been a catch-up of somatic growth such that the experimental animal (to the rear) is now only marginally smaller than its sibling control (to the front). c) Control P150 lung. d) Dex-treated lung at P150. Scale bars $=50 \mu \mathrm{m}$. 

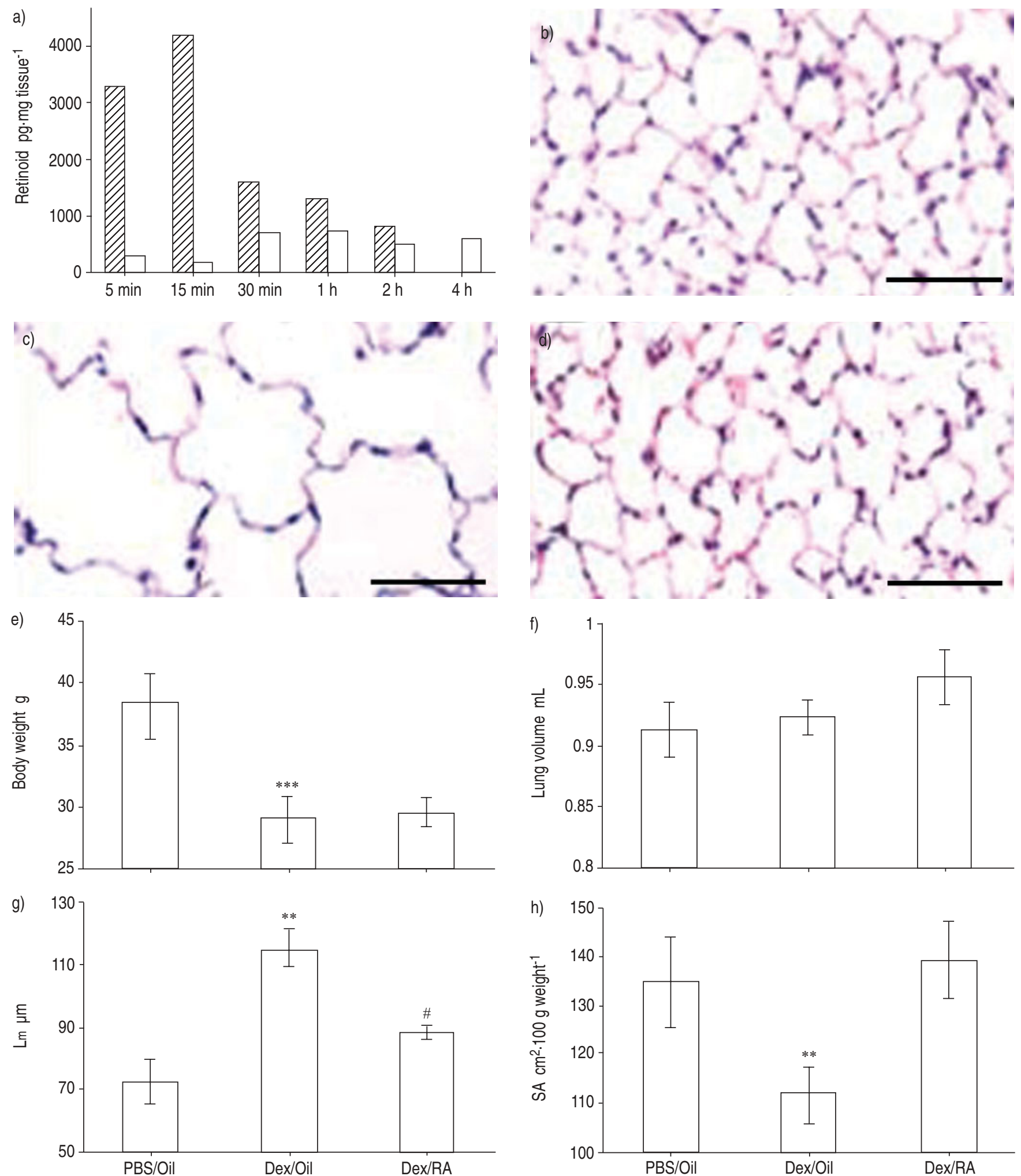

Fig. 5.-a) High performance liquid chromatography analysis of lung all-trans-retinol ( $\square$ ) and all-trans-retinoic acid (RA; $\mathbb{Z})$ following a single intraperitoneal dose of all-trans-RA. RA arrives in the lung within 5 min and there is a peak within 15 min. This falls to near undetectable levels within $4 \mathrm{~h}$. There is no significant change in retinol levels. The structure of the lung at P90 is shown in b) control lung, c) dexamethasone (Dex)treated lung, which results in fewer larger alveoli and d) RA-treated lung, which rescues the disrupted phenotype and restores the alveolar structure and number. Scale bars $=50 \mu \mathrm{m}$. e) Body weights of the animals at P90. Dex dosing (Dex/oil) results in a significant reduction in body mass and RA treatment (Dex/RA) has no significant effect on body weight. f) Lung volumes at P90. There is no significant difference in lung volume between the three groups. g) Mean chord length $(\mathrm{Lm})$ at P90. Dex treatment results in a significantly increased Lm compared with controls (phosphate-buffered saline (PBS)/oil). RA treatment results in a significant reduction in $\mathrm{Lm}(\mathrm{p}<0.01)$ compared with Dex towards that of the control animals. h) Surface area (SA) of lung per $100 \mathrm{~g}$ body weight at P90. Dex dosing results in significantly reduced SA per $100 \mathrm{~g}$ compared with controls. RA restores the SA per $100 \mathrm{~g}$ such that there is no significant difference between the RA group and the control group. **: $\mathrm{p}<0.01$ versus control; ***: $\mathrm{p}<0.001$ versus control; ${ }^{\#}: \mathrm{p}<0.01$ versus Dex. 
shown) and lung within 5 min (fig. 5a) and a peak within $15 \mathrm{~min}$. RA levels rise to a maximum of $4,178 \mathrm{pg} \cdot \mathrm{mg}$ tissue $^{-1}$ at $15 \mathrm{~min}$, fall by more than half to $1,604 \mathrm{pg} \cdot \mathrm{mg}^{-1}$ at $30 \mathrm{~min}$ and are almost undetectable at $4 \mathrm{~h}$ (fig. 5a). Furthermore, in all cases it was still all-trans-RA that was present in the lung, it had not been metabolised to another isoform. This suggests a rapid transfer and metabolism of administered RA in the lung. This concept is supported by earlier studies demonstrating a rapid induction of genes known to contain a retinoic acid response element (RARE), such as retinoic acid receptor (RAR) $\beta$, and cellular retinol-binding protein (CRBP)I messenger ribonucleic acid (mRNA) following systemic RA dosing $[26,27]$.

\section{Exogenous retinoic acid rescues the dexamethasone- treated adult lung}

Knowing that Dex treatment is permanent and that intraperitoneal RA will rapidly travel to the lung, the effect of RA on alveolar structure could now be examined. Groups $(n=7-8)$ of adult mice that had been treated with Dex from P2-14 were dosed with either RA in oil or oil only from P30-42. The animals were killed at P90 and their lungs removed for morphometric analysis. Calculating the $\mathrm{Lm}$ by intersection counting and the lung volume by displacement measurement, can derive the SA [20]. SA was normalised to body weight to eliminate the effect of body weight on alveolar number and to permit valid comparisons between individual animals and between control and Dex-treated groups. Dex dosing from P2-24 resulted in a significant $(\mathrm{p}<0.01)$ decrease in body weight at P90 (fig. 5e). RA had no significant effect on body weight (fig. 5e). Dex treatment appeared to increase lung volumes but this was not statistically significant (fig. $5 f$ ). Dex dosing resulted in a significantly increased $(p<0.01) \mathrm{Lm}$ at P90 (fig. $5 \mathrm{~g}$ ) reflecting fewer, larger airspaces as shown in figure $5 \mathrm{c}$ versus figure $5 \mathrm{~b}$. The $\mathrm{Lm}$ in the Dex/RA group was significantly lower $(\mathrm{p}<0.01)$ than the Dex-only group (fig. $5 \mathrm{~g}$ ) suggesting that RA restored $\mathrm{Lm}$ toward control values. Dex treatment results in a significantly reduced $(\mathrm{p}<0.01)$ SA per $100 \mathrm{~g}$ (fig. 5h), and RA restored the SA per $100 \mathrm{~g}$ such that there was no significant difference between the control group and the Dex/RA group. Therefore, RA restored the SA/body weight of these Dex-treated animals.

The data in figures $5 \mathrm{e}-\mathrm{h}$ are from pooled groups of male and female mice. The morphometric data from this experiment are presented in table 1 with separate male and female data. It can be seen here that differences between males and females can readily be detected within groups in terms of body weight, Lm and gas-exchanging SA per $100 \mathrm{~g}$ body weight. However, when the data are analysed separately in this way the result is the same for both males and females, i.e. RA restores the Dex-treated gas-exchanging surface to normal.

Light microscopy confirmed that Dex treatment during alveologenesis dramatically disrupted alveolar architecture (fig. 5c) compared with that of a control lung (fig. 5b) at P90. In Dex-treated animals (fig. 5c), there are fewer, larger alveoli and a less complex alveolar structure consistent with the morphometry data demonstrating a reduced SA. RA treatment from P30-42 resulted in smaller, more numerous alveoli and a more complex alveolar structure at P90 (fig. 5d) that was identical to the control lungs (fig. 5b). Again, this is in agreement with morphometric analyses demonstrating a reduction in $\mathrm{Lm}$ and restoration of SA.

\section{Discussion}

A mouse model of induced alveolar regeneration has been characterised and the previous work of MASSARO and MASSARO [3, 28] showing that RA can induce regeneration of the adult mammalian lung has been confirmed. However, the present observations were only concerned with histological aspects of the regenerated lung, since testing lung function in mice is very difficult. It is important to note that in the rat, where lung function can be measured, no effect was seen with RA [29]. Nevertheless, this ability of RA to regrow the mouse lung suggests that mammals may have more intrinsic regenerative ability than was recognised previously. This phenomenon in the mouse was specifically chosen for characterisation because of the availability of transgenic technology, and in future experiments the authors intend to determine the source of cells that generates the regenerated tissue.

Several lines of evidence suggest that lipofibroblasts may be a potential target of exogenous RA in the regenerating lung. It has been demonstrated that lipofibroblasts are present in the lung during alveologenesis [30-34] and that they undergo significant numerical changes during this period $[29,35,36]$. These cells are the retinoid storage cells of the lung [37] similar to the Ito cell or stellate cell in the liver. Furthermore, lipofibroblasts are a major source of tropoelastin synthesis [34] and they can synthesise tropoelastin in response to RA [15]. Interestingly, ultrastructural analysis has demonstrated that lipofibroblasts are often in close contact with type-II pneumocytes [38], which can be considered as a lung progenitor cell population and a potential source of type-I cells. Type-II cells are known to also possess the RA signal transduction components [39] so it is possible that the type-II cell may also be involved in the coordinated eruption of a developing alveolar septa. Another interesting possibility is that a circulating "stem cell" population may exist, on which RA may act to seed the damaged lung. Recent evidence suggests that following damage, lung epithelium can be repopulated by a bone marrow-derived multipotent stem cell [40, 41]. These

Table 1. - Data on sex, weight, lung volume (LV) and mean chord length (Lm) for the effect of dexamethasone (Dex) followed by retinoic acid $(\mathrm{RA})$

\begin{tabular}{|c|c|c|c|c|c|c|c|}
\hline Group & Sex $n$ & Weight $g$ & $\mathrm{LV} \mathrm{cm} \mathrm{cm}^{2}$ & $\mathrm{LV} /$ weight $\mathrm{cm}^{3} \cdot \mathrm{g}^{-1}$ & $\mathrm{Lm} \mu \mathrm{m}$ & $\mathrm{SA} \mathrm{cm}^{3}$ & $\begin{array}{l}\text { Normalised SA to } \\
\text { weight } \mathrm{cm}^{2} \cdot 100 \mathrm{~g}^{-1}\end{array}$ \\
\hline \multirow[t]{2}{*}{ PBS/oil } & M 6 & $40.9 \pm 1.2$ & $0.938 \pm 0.01$ & 0.022 & $74.85 \pm 1.39$ & 501.3 & 122.57 \\
\hline & F 2 & $29.7 \pm 12.8$ & $0.833 \pm 10.06$ & 0.028 & $68.06 \pm 3.27$ & 489.5 & 164.81 \\
\hline \multirow[t]{2}{*}{ Dex only } & M 3 & $29.9 \pm 1.82$ & $0.958 \pm 0.01$ & 0.032 & $127.77 \pm 5.97$ & 299.9 & 100.34 \\
\hline & F 4 & $26.9 \pm 1.60$ & $0.897 \pm 0.01$ & 0.033 & $104 / 43 \pm 5.24$ & 343.6 & 127.73 \\
\hline \multirow[t]{2}{*}{ Dex/RA } & M 6 & $31.98 \pm 0.55$ & $0.987 \pm 0.02$ & 0.031 & $88.89 \pm 4.46$ & 444.1 & 138.87 \\
\hline & F 4 & $25.62 \pm 0.62$ & $0.911 \pm 0.03$ & 0.035 & $84.113 \pm 6.94$ & 433.2 & 169.13 \\
\hline
\end{tabular}

SA: surface area; PBS: phosphate-buffered saline. 
two scenarios as a source of the regenerated cells can now be tested with the appropriate transgenic mouse strains.

The hypothesis that an organ regenerates using the same gene pathways that it used during development is a common one in regenerative biology. In the case of the lung, the present authors and others have provided much data to demonstrate that RA is required for alveolar development. Alveoli develop postnatally in rats, mice and humans and here it is shown that when disulphiram is administered to newborn mice, alveologenesis is inhibited. Although it is clear that disulphiram is not a specific inhibitor of RA synthesis, since it also inhibits other enzymes, this evidence along with the previous demonstration of the presence of the RA-synthesising enzymes RALDH1 and RALDH2, the retinoid-binding proteins CRBP I, CRBP II and cellular retinoic acid-binding protein I, the retinoic acid-receptor isoforms RAR $\alpha 1, \mathrm{RAR} \alpha 2$, RAR $\beta 4$ and RAR $\gamma 2$, and the presence of retinol and RA themselves [13, 14, 16-18], provides strong support for the notion that RA is indeed required for alveologenesis. Other supporting evidence includes the fact that citral, another aldehyde dehydrogenase inhibitor disrupts tropoelastin mRNA and elastin levels [15] and the RAR $\gamma$ null mutant mouse fails to form alveoli correctly [19].

In order to examine the regeneration of alveoli, a robust and repeatable model of either alveolar destruction or disrupted development was required with which to assay the effect of RA. Dex treatment was shown to inhibit alveolar development and these animals had fewer, larger alveoli and a reduced gas-exchanging SA. The effect on alveolar architecture remained obvious for at least 150 days. Recent work by TSCHANZ et al. [42] has suggested that rat lungs can recover from glucocorticoid adminstration by day 60 , but in this case the treatment time was shorter than that used here. Indeed, in the present work, the effect of Dex could be titrated by varying either the dose or duration of dosing. It is possible that Dex has its effect by affecting RA itself or a component of the RA signalling pathway. Previous studies in neonatal rats treated with Dex have demonstrated that there is a reduction in RAR $\beta$ [43] and CRBP I [44]. Since both of these genes contain a RARE, this result may reflect the affect of Dex on RA levels. Furthermore, there is an imperfect glucocorticoid response element within $1 \mathrm{~kb}$ of the start site of the human Aldh-1 gene suggesting that Dex could directly regulate Aldh-1 transcription. Alternatively, there are many other potential sites for interaction between Dex and RA, since both retinoids and glucocorticoids act via nuclear receptors of the same superfamily.

Finally, it was shown that when RA was delivered intraperitoneally it reached the lung within $5 \mathrm{~min}$, still as all-trans-RA, followed by a rapid decline and after $4 \mathrm{~h}$ the levels in both blood and lung had returned to normal adult levels. In retinol-deprived rats, both RAR $\beta$ [27] and CRBP I [26] mRNA were rapidly induced, in $4 \mathrm{~h}$ and in $1 \mathrm{~h}$, respectively, in lung tissue following systemic RA.

These data demonstrate that exogenous retinoic acid is rapidly delivered, it is not metabolised to other compounds and that retinoic acid-responsive genes are activated in the lung following systemic dosing. The important question that must now be answered in an effort to understand the molecular basis of this regenerative phenomenon is what are the other genes that retinoic acid activates in the lung? These retinoic acid pathway genes, retinoic acid receptor- $\beta$ and cellular retinol-binding protein I, are presumably immediate retinoic acid targets. Genes, such as tropoelastin, whose protein elastin is the major structural component of the alveolus and that is known to be regulated by retinoic acid [45], are likely to be final downstream targets. It is what lies in between these two that is the interesting question, which hopefully will be answered in the near future.

\section{References}

1. Goss RJ, ed. Principles of Regeneration. New York, Academic Press, 1969.

2. McKay R. Stem cells in the central nervous system. Science 1997; 276: 66-71.

3. Massaro GDC, Massaro D. Retinoic acid treatment abrogates elastase-induced pulmonary emphysema in rats. Nat Med 1997; 3: 675-677.

4. Murray CJL, Lopez AD, eds. The Global Burden of Disease. A Comprehensive Assessment of Mortality and Disability from Diseases, Injuries and Risk Factors in 1990 and Projected to 2020. Cambridge, World Health Organization, 1996.

5. Barnes PJ. Chronic obstructive pulmonary disease. New Engl J Med 2000; 343: 270-278.

6. Belloni PN, Garvin L, Mao CP, Bailey-Healy I, Leaffer D. Effects of all-trans-retinoic acid in promoting alveolar repair. Chest 2000; 117: 235S-241S.

7. Tepper J, Pfeiffer J, Aldrich $\mathbf{M}$, et al. Can retinoic acid ameliorate the physiologic and morphologic effects of elastase instillation in the rat? Chest 2000; 117: 242S244S.

8. Srinivasan G, Bruce EN, Houtz PK, Bruce MC. Dexamethasone-induced changes in lung function are not prevented by concomitant treatment with retinoic acid. $\mathrm{Am}$ J Physiol Lung Cell Mol Physiol 2002; 283: L275-L287.

9. Lucey EC, Goldstein RH, Bruer R, Rexer BN, Ong DE, Snider GL. Retinoic acid does not affect alveolar septation in adult FVB mice with elastase-induced emphysema. Respiration 2003; 70: 200-205.

10. Maden M, Pizzey J. The role of retinoids in patterning fish, amphibian, and chick embryos. In: Sherbet GV, ed. Retinoids: Their Physiological Function and Therapeutic Potential. Volume 3. Greenwich, JAI Press Inc., 1997; pp. 93-139.

11. Ross SA, McCaffery PJ, Drager UC, De Luca LM. Retinoids in embryonal development. Physiol Rev 2000; 80: 1021-1054.

12. Maden M. Retinoid signalling in the development of the central nervous system. Nat Rev Neurosci 2002; 3: 843853.

13. Geevarghese SK, Chytil F. Depletion of retinyl esters in the lungs coincides with lung prenatal morphological maturation. Biochem Biophys Res Comm 1994; 200: 529-535.

14. Hind $\mathrm{M}$, Corcroan J, Maden M. Alveolar proliferation, retinoid synthesising enzymes and endogenous retinoids in the postnatal mouse lung. Different roles for Aldh-1 and Raldh-2. Am J Respir Cell Mol Biol 2002; 26: 67-73.

15. McGowan SE, Doro MM, Jackson SK. Endogenous retinoids increase perinatal elastin gene expression in rat lung fibroblasts and fetal explants. Am J Physiol 1997; 273: L410-L416.

16. Hind M, Corcoran J, Maden M. Temporal/spatial expression of retinoid binding proteins and RAR isoforms in the postnatal lung. Am J Physiol Lung Cell Mol Physiol 2002; 282: L468-L476.

17. McGowan SE, Harvey CS, Jackson SK. Retinoids, retinoic acid receptors, and cytoplasmic retinoid binding proteins in perinatal rat lung fibroblasts. Am J Physiol 1995; 269: L463L472.

18. Ong DE, Chytil F. Changes in the levels of cellular retinol and retinoic acid binding proteins of the liver and lung during perinatal development. Proc Natl Acad Sci USA 1976; 73: 3976-3978.

19. McGowan SE, Jackson SK, Jenkins-Moore M, Dai HH, Chambon P, Snyder JM. Mice bearing deletions of retinoic acid receptors demonstrate reduced lung elastin and alveolar numbers. Am J Respir Cell Mol Biol 2000; 23: 162-167.

20. Weibel ER. Morphometry of the Human Lung. Berlin, Springer-Verlag, 1963.

21. Thaller C, Eichele G. Identification and spatial distribution 
of retinoids in the developing chick limb bud. Nature 1987; 327: 625-628.

22. Achkar CC, Derguini F, Blumberg B, et al. 4-oxoretinol, a new natural ligand and transactivator of the retinoic acid receptors. Proc Natl Acad Sci USA 1996; 93: 4879-4884.

23. Stratford T, Horton C, Maden M. Retinoic acid is required for the initiation of outgrowth in the chick limb bud. Curr Biol 1996; 6: 1124-1133.

24. Massaro D, Teich N, Maxwell S, Massaro GD, Whitney P. Postnatal development of alveoli. Regulation and evidence for a critical period in rats. $J$ Clin Invest 1985; 76: 1297-1305.

25. Tschanz SA, Damke BM, Burri PH. Influence of postnatally administered glucocorticocoids on rat lung growth. Biol Neonate 1995; 68: 229-245.

26. Haq R, Chytil F. Retinoic acid rapidly induces lung cellular retinol-binding protein $\mathrm{mRNA}$ levels in retinol deficient rats. Biochem Biophys Res Comm 1988; 156: 712-716.

27. Haq R, Pfahl M, Chytil F. Retinoic acid affects the expression of nuclear retinoic acid receptors in tissues of retinoldeficient rats. Proc Natl Acad Sci USA 1991; 88: 8272-8276.

28. Massaro GD, Massaro D. Retinoic acid treatment partially rescues failed septation in rats and in mice. Am $J$ Physiol 2000; 278: L955-L960.

29. Srinivasan G, Strange J, Awonusonu F, Bruce MC. Insulinlike growth factor I receptor is downregulated after alveolarization in an apoptotic fibroblast subset. $\mathrm{Am}$ J Physiol Lung Cell Mol Physiol 2002; 282: L457-L467.

30. Wake K. Perisinusoidal stellate cells (fat-storing cell, interstitial cells, lipocytes), their related structure in and around the liver sinusoids, and vitamin A-storing cells in extrahepatic organs. Int Rev Cytol 1980; 66: 303-353.

31. Maksvytis HJ, Vaccaro C, Brody JS. Isolation and characterisation of the lipid-containing interstitial cell from the developing rat lung. Lab Invest 1981; 45: 248-259.

32. Brody JS, Kaplan NB. Proliferation of alveolar interstitial cells during postnatal lung growth: evidence for two distinct populations of pulmonary fibroblasts. Am Rev Respir Dis 1982; 127: 763-770.

33. Kaplan NB, Grant MM, Brody JS. The lipid interstitial cell of the pulmonary alveolus: age and species differences. $\mathrm{Am}$ Rev Respir Dis 1985; 132: 1307-1312.
34. McGowan SE, Torday JS. The pulmonary lipofibroblast (lipid interstitial cell) and its contributions to alveolar development. Ann Rev Physiol 1997; 59: 43-62.

35. Awonusonu F, Srinivasan S, Strange J, Al-Jumaily W, Bruce MC. Developmental shift in the relative percentages of lung fibroblast subsets: role of apoptosis postseptation. $\mathrm{Am}$ J Physiol Lung Cell Mol Physiol 1999; 277: L848-L859.

36. Bruce MC, Honaker CE, Cross RJ. Lung fibroblasts undergo apoptosis following alveolarization. Am J Respir Cell Mol Biol 1999; 20: 228-236.

37. Okabe T, Yorifuji H, Yamada E, Takaku F. Isolation and characterisation of vitamin-A-storing lung cells. Exp Cell Res 1984; 154: 125-135.

38. Sannes PL. Structural and functional relationships between type II pneumocytes and components of extracellular matices. Exp Lung Res 1984; 17: 639-659.

39. Naltner A, Ghaffari M, Whitsett JA, Yan C. Retinoic acid stimulation of the human surfactant protein $\mathrm{B}$ promoter is thyroid transcription factor 1 site-dependent. $\mathrm{J} \mathrm{Biol} \mathrm{Chem}$ 2000; 275: 56-62.

40. Kotton DN, Ma BY, Cardoso WV, et al. Bone marrowderived cells as progenitors of lung alveolar epithelium. Development 2001; 128: 5181-5188.

41. Krause DS, Theise ND, Collector MI, et al. Multi-organ, multi-lineage engraftment by a single bone marrow derived stem cell. Cell 2001; 105: 369-377.

42. Tschanz SA, Makanya AN, Haenni B, Burri PH. Effects of neonatal high-dose short-term glucocorticoid treatment on the lung: a morphologic and morphometric study in the rat. Pediatr Res 2003; 53: 72-80.

43. McMenemy KR, Anderson MJ, Zachman RD. Effect of dexamethasone and oxygen exposure on neonatal rat lung retinoic acid receptor proteins. Pediatr Pulmonol 1994; 18: 232-238.

44. Whitney D, Massaro GD, Massaro D, Clerch LB. Gene expression of cellular retinoid-binding proteins: modulation by retinoic acid and dexamethasone in postnatal rat lung. Pediatr Res 1999; 45: 2-7.

45. Liu B, Harvey CS, McGowan SE. Retinoic acid increases elastin in neonatal rat lung fibroblast cultures. Am J Physiol 1993; 265: L430-L437. 